\title{
Succession Planning as a Key to Effective Managerial Transition Process in Corporate Organizations
}

\author{
Oyewole Oluwaseun Oduwusi \\ Human Resources Department, APIN Public Health Initiatives, Abuja, Nigeria
}

Email address:

wolewusi@yahoo.com

To cite this article:

Oyewole Oluwaseun Oduwusi. Succession Planning as a Key to Effective Managerial Transition Process in Corporate Organizations. American Journal of Management Science and Engineering. Vol. 3, No. 1, 2018, pp. 1-6. doi: 10.11648/j.ajmse.20180301.11

Received: March 14, 2018; Accepted: April 27, 2018; Published: May 15, 2018

\begin{abstract}
Succession planning is a vital element in the current scenario of tight managerial transition process in competitive business environments. Identifying and developing potential successors for key positions in an organizations through systematic evaluation process and training of competent employee for transition processes is fundamental for the success of every organization. Often time, the least qualified person or unprepared person to fill the vacant position takes over the leadership thereby leading the organization into corporate oblivion. This paper reviewed the roles of succession planning in the process of replacing key positions in an organization. From the review, many organizations experience breakdown as a result of poor succession planning whereas corporate succession planning is essential for any organization that is on the trail of achieving excellent managerial transition. This therefore recommends the establishment of effective succession planning in order to enhance organizational success. Nigerian companies must also ensure the introduction of succession planning as a matter of deliberate policy and build it into their strategic plan which must be reviewed regularly.
\end{abstract}

Keywords: Succession, Planning, Managerial, Transition Process, Corporate Organizations

\section{Introduction}

The essence of succession planning is to ensure effectiveness of managerial transition process in corporate organizations for risks associated with the planned or unplanned loss of knowledge that is critical to the success of the organization.[1] described succession planning as the identification and development of potential successors in an organization which planning prepares for future critical vacancies of management positions by forecasting the talent necessary for these roles to provide the groundwork and understanding of the characteristics needed to maintain an organization's strategic plan. [2] Succession planning model develops employees to ensure that the organization has highly qualified employees who are capable of filling critical positions. Succession planning is a key element to both workforce planning and strategic planning in every corporate organization. [3] affirmed that the organization needed to reevaluate its current succession planning model to ensure that it is applied appropriately at all levels of the agency. [4] Preparing employees for promotion in order to ensure continuity of optimal performance when they advance to key positions following departures owing to retirement, promotion, retrenchment or death of incumbents is what succession planning is about. [5] Observes that succession planning from an organizational viewpoint comprises risk assessment in key positions, minimizing risk through appropriate compensation, recognition and management, and assuring the readiness of successors by identifying and training high potential employees. Despite the many benefits of having a succession plan in managerial transition, many companies neglect to develop such plans that will encourage effective organizational performance and most organizations do not practice succession planning and replacement of disengaged staff is not done in a systematic manner. This review therefore discuss the impact of succession planning in managerial transition process.

\section{Theoretical Background of Succession Planning}

Succession planning is a method of grooming less tenured staff to ensure the availability of a supply of capable staff 
who are ready to assume key or critical position. [6] Succession planning was viewed as an ongoing dynamic process that assists a business or organization in aligning its goals and its human capital needs as it prepare companies for future critical vacancies of middle and senior management positions. [7] State that the three basic goals of succession planning include: identification of critical management positions within the organization, identification of future vacancies in those positions, and identification of managers who would potentially fit into these vacancies. The approach is systematic and a multi-step process which includes gaining a thorough understanding of the current workforce, envisioning the operating environment that will most likely exist in the future, identifying the competencies needed that will move the company forward to seize those future opportunities and thrive, and developing strategies for building that future workforce and human resource function as positioned in the organization.[8-9] In many cases, succession planning targets the most important positions in an organization, usually a candidate from within the organization is nurtured and developed over the years. He or she must have displayed 'skills, knowledge, leadership qualities, experience, and desire' required for such a grooming exercise. [10] There are four main components to Leadership Succession Planning. The first component is identifying the potential successor; the process of selecting a suitable candidate to take reigns of the business upon the departure of the current CEO begins with the identification of at least one and preferably more than one candidate and should begin as soon as possible and long before the CEO decides to step down. The second component is changing management style: something that can be both a hallmark and at times can be an identified weakness of many organizations is the CEO's management style. The third component is successor training and development: the principle function of the CEO in helping assure the success of his or her successor lies in the appropriate leadership development of the candidate. The fourth and final component is selecting the successor: there are many factors that will qualify an individual to lead and manage a business. Those factors should include knowledge, skills, abilities, motivation, ambition, temperament, formal education and experience.

\section{Models of Succession Planning}

Succession planning model represent an integral part of succession planning as it allows firms to identify and develop internal candidates with a clear objective to fill senior-level positions as and when they become available. There are mainly three models of succession planning organizations as published by [11] these are: (1) short term planning or emergency replacements, (2) long term planning or managing talent, and (3) combination of above plans. Firstly, the short term planning or emergency replacements is the most common model of succession planning and serves as a crucial point for all types of businesses. Secondly, long term planning or managing talent is based on the strategic frame work for organization's future goals; key positions necessary for growth are identified as well as the best candidates to fill those roles. Some organizations invite all employees to take part in assessment processes, which help identify talent to be developed for the future needs of the organization. Organizations that wish to groom leaders from within their existing talent pool employ talent management as a key component of its long term human capital strategy [12]. The third is the combination model that combines both plans, allowing senior management to plan for the long term growth of both the organization and employees within the organization and prepare for emergency replacements to ensure that business is not affected by knowledge loss or lack of skilled employees.

\subsection{Framework for Succession Planning}

It is not a walk in the park to set a succession plan in motion. The shape and vision of one company differs to another. It has been discovered that over $90 \%$ do not have a succession plan [13] aside big organizations with boards of directors such as Coca Cola, Pepsi, Eleganza, Literamed Publications, and a few others, many Nigerian businesses fail to work with an efficient succession plan. Succession laws and the multi-cultural constitution of Nigeria are stumbling blocks to smooth succession in family-owned businesses. [14] The chaos or strife that often follows the death of a founder -inheritance issues- also militate against the continuity of family enterprises. [15-16] Proposes some factors responsible for a lack of efficient succession planning. These are: owners' confidence of continued sound health; lack of interest by potential successor; entrepreneurs' lack of knowledge of what succession planning entails. [17] Advises that there is also a need to focus resources on retaining key employees. Without question, any succession plan, no matter how well laid out, will fail if key employees are not retained by the organization.

\subsection{Importance of Succession Planning}

Succession planning prepares an organization for the time when a key member or members of the work force moves on. It creates a steady supply of talented, motivated and qualified persons who are groomed and ready to take over at a moment's notice when the eventuality happens. [18] Succession planning ensures that the management team and the Human Resource department share a vision concerning the staffing needs of the organization and ensures that there are no staffing gaps.

\subsection{Benefits of Succession Planning in an Organization}

Succession planning is critical to the sustainability and competitive advantage of any Organization irrespective of its ownership nature. Thus, succession planning facilitates the organization to take a strategic approach to its leadership development and employee skill assessment. [19] It is particularly important where the Government policy causes 
massive retirements in order to preserve critical organizational knowledge. According to [3], succession planning also facilitates a flow of talent emerging from within the organization. This is also capable of boosting the confidence in staff. This point is supported by the findings of who observes that succession planning is a tool for talent management in organization, and it is crucial for attracting, keeping and promoting special talents that helps an organization to remain competitive. [20]

\section{Elements of Succession Planning}

\subsection{Top Management Participation \& Support}

Before succession planning can be implemented in any organization, it must obtain the full support of the organization's executive and management staff. "A commitment by the city or county manager and alignment with organizational strategy" is a necessary element to any succession plan. Without this support, even if a succession plan is identified, the plan will never take flight within the culture of the agency. As Ley found in her study, a lack of senior management support hindered open access to the organization's leaders," and thus limited interest in succession planning at the agency in her study [20]. Executives and "managers are uniquely positioned to assess how their business will be carried out and to identify the human capital capabilities needed to do so effectively.

\subsection{Criteria for Organizational Succession Planning}

A good succession planning program allows existing senior executives to observe people over time and train them to be of use to the company, its needs, and its culture. [21] Succession planning should be incorporated into employee performance evaluations, and it is the responsibility of management to see to it that employees are aware of the concepts and processes involved. Managers in the public sector "must learn to consider not only what can be, but what will be, and how what is achieved can be sustained. [22]

\subsection{Needs Driven Assessment}

In order to create an effective succession planning model, an assessment of current employees' skills and interests must be completed. Through a needs driven assessment, an organization can identify what positions are mission critical and what skill sets are necessary for performing the duties required of those positions. Mission critical, or key positions in an agency, are those "that have a significant impact on the work that needs to be performed. Explains that it is necessary to perform a needs assessment, as it is essential to identify critical skill sets in order to determine how to most effectively implement all succession planning criteria, such as training requirements. An effective way to conduct this assessment is through a checklist including ratings of competency levels such as: advanced, intermediate, beginning or none." Ideally, "each manager and employee should conduct the assessment, and then collaborate on the results. [30] Succession planning done well involves preparing the agency for a change in leadership, but it also includes assessing what has been valuable and how that can be preserved" in the future. [23-24]

\subsection{Provision of Professional Development Opportunities}

Beyond identifying what skill sets and knowledge bases are required for key positions, it is crucial that a succession plan provide a method or plan for providing employees the opportunity for professional development, as it has been determined that a background characteristic of top managers which has attracted attention in the strategic leadership literature is functional track experience. [25] In other words, since experience and job knowledge are highly valued for succession, it is necessary that organizations provide employees with the opportunity to develop and advance these skills. While formal training can be useful for developing an employee's knowledge and skill base, organizational knowledge is gained primarily through experience. [26]

\subsection{Focus on Individual Attention}

In a performance based selection system, individual employees can be put in a leadership track by being given a special assignment that allows him or her opportunity to grow which often, leadership tracks are guided by career paths, which provide employees with a road map or stepping stones allowing them to move from their current position to their desired promotion. In order to make employees accountable for this developmental responsibility, advancements in the career path should be explicitly outlined in the employee performance evaluation. [27] In the performance evaluation, employees can be credited for their individual competencies, which are those competencies "that each employee brings to his or her function during the performance evaluation, "individuals and managers should discuss performance, potential and development and contribute constructively to the implementation of development plans and dovetailing the career development plan with the succession plan provides exponential value to the company as well as to its employees. [28]

\subsection{Dedicated Responsibility}

Succession plan should have a project planner assigned to oversee it and ensure that the plan stays current. Without an employee dedicated to ensuring that the program is being utilized, there will be no accountability for the plans success. Without a designated program coordinator and known training needs, tracking of the participants in succession planning is difficult and poorly performed as well as have both the management and employee perspectives in mind in order to track future succession planning needs of the agency. [29]

\subsection{Extends to All Levels of Organization}

Most often, when creating a succession plan, agencies focus on upper level management positions, but in actuality, 
there are many positions throughout an agency that are critical to its success, thus in implementing a succession plan, agencies should identify talent at all levels. In addition to management positions, other positions that are often chosen for succession planning are "information technology specialists, statistical analysts, and front-line processors. [30]

\subsection{Challenge of Succession Planning in Nigeria}

Nigerian companies have died because of poor succession and the succession problems we have in Nigeria are similar with those in other African countries. [31] Nigeria is an emerging economy with a very complex business environment however, the following are some of the succession challenges typical in the Nigerian business environment. [32]

\subsubsection{Lack of Succession Planning}

As a matter of fact, lack of effective succession planning has been a worldwide challenge. More than half of the companies operating today cannot name a successor to the CEO should the need suddenly arise which could be very problematic for the person leaving as well as the person expected to take over. [33] But in Nigeria, the situation is worse as many of the organizations lack the skills to effect a smooth transition of leadership. Succession crisis: Research has established the fact that the major difference between organizations that manage success well and those that don't is the understanding that succession is a process, not an event. Transition in leadership is crisis-laden in Nigeria mostly because of this.

\subsubsection{Polygamous Family}

In the recent Past, a typical successful African entrepreneur will often acquire more wives. Unfortunately, this often creates huge succession problems, especially when he dies. The rivalry between the siblings and spouses that follows the demise of polygamous entrepreneurs, coupled with a variety of cultural laws guiding inheritance in Nigeria, often does not make room for the objective selection of the best material as successor. [34]

\subsubsection{Intestate Succession}

The law of nature dictates that everyone must of necessity die someday. But it has been shown that many Nigerian businessmen are reluctant to make a will. Some think that making a will at mid-age is like inviting death. This leads to a delay in the execution of the will while the legal dispute persists, often with disastrous consequences to the continuity of such businesses. [35] Therefore, it becomes mandatory that founders and business owners should write their wills at the earliest opportunity and ensure that such wills are properly filed to minimize legal disputations at execution. [36] Choice of successors should be based on the future direction of the company or anticipated needs of the company. When the company is innovating, a creative or research-inclined successor is appropriate; when the company plans to expand, then a man with marketing skills may be best; whereas when the company is consolidating, a successor candidate with finance skills may be considered. [37]

\subsection{Advantages of External Recruitment}

Recruiting externally brings new ideas and talent to the organization as it opens up opportunities to find experienced and qualified candidates and may also help develop a diverse team of employee [38] It is important to point out that many companies prefer to look outside their organizations for the replacement needed when a vacuum is created, one of such advantages is that the management team is able to focus on running the organization while its human resources department oversees the internal demand of keeping staff productivity at optimal level rather than stretch personnel and resources in searching for and pooling suitable candidates to execute a succession plan. [39]

\subsection{Strategy for Effective Succession Planning}

Effective succession planning addresses the needs of an organization as the senior management ages. This is vital since there is the inclination to ignore issues of succession for a variety of reasons. In the African society, the thought of dying is hardly a pleasant one and many sole business owners fall into that category. [40] It is the same reason many die intestate, having failed to provide a will before their death. These determine the direction and preoccupation of the organization. [41] Sadly, daily engagements and a lack of interest in succession issues have channeled many organizations' towards that very end. An effective succession plan prevents this by ensuring that someone or some persons have been prepared over the years to step into any high ranking vacant positions and provide a link between the past and the future [42] A comprehensive succession planning strategy encompasses various activities, which provide a roadmap for developing succession plans. Firstly, there must be assessment of key positions in terms of competencies and experiences needed to qualify for leadership positions. [43] Then identify key talents at the top two or three levels in the organization through management assessment of their performance and potential for advancement. Secondly, assess key talents, primary development needs of skills ready for the next level and strategies for potential successors through ${ }^{\text {ee }} \mathrm{s}$ formal education, training, leadership and management training, coaching or mentoring and job enrichment. Lastly, monitor implementations of the employee development plans with annual reviews and implementation of transition plan to select leaders from the talent pool to fill the vacancies. Usually there are three succession planning with internal skills, and talent pool planning for training for future successions and replacements. [44-46]

\section{Conclusion and Recommendations}

This review showed that succession planning is unarguably an essential factor that every organization with sustainability in mind must focus on and it requires 
managerial supervision and devotion of resources on a rolling basis.

This study therefore made the following recommendations with respect to the reviewed literature on succession planning.

To reposition organization for effective performance and service delivery, there is need for organizations to establish effective succession planning through training of competent employees prior to superior staff termination of appointment.

Nigerian companies must ensure the introduction of succession planning as a matter of deliberate policy and build it into their strategic plan, which must be reviewed regularly.

All successors should be trained and ensure that they have proper skills in place before they proceed over the predecessor to ensure continuity of the business.

A good communication channel should be put in place to aid in flow of information to avoid conflicts.

\section{References}

[1] Susan J, \& Kowalewski, D. (2011). Succession Planning: Evidence from "Best Companies in New York. International Journal of Management and Marketing Research (4)2.

[2] Rollinson, R. (2017). The Most Important Factors of Strategic. Planning Center for Excellence in Public Leadership. (919): 460-8180.

[3] Human Resource (2009). The Importance of Succession Planning: Developing a Winning Human Resource Mission Statement.

[4] Board of Directors, North American Public \& Private Sectors (2010). Preparing Employees Performance Appraisal for Effective Service Delivery. Pp 32-56.

[5] Farley, A. (2005), HR ${ }^{\text {ee }}$ S Role in Talent Management and Driving Business Results, Employment Relations Today.

[6] Robb, (2006). "Succeeding with Succession: tools for succession management get more sophisticated". HR Magazine January.

[7] Butler, Kevin \& Roche-Tarry, Dona E. (2002). Succession planning: Putting an organization's knowledge to work, Nature Biotechnology, (10):202-2011.

[8] Orellano, T. \& Miller, J. (1997). Succession planning: Lessons from Kermit the frog. SHRM HR Resources Information Center.

[9] Morfeld, C. (2005, February). Workforce planning: the strategy behind "strategic staffing". SHRM

[10] Johnson, J. A. (2016). Succession planning and Transition Management: A Lived Experience. Journal for Nurses in Professional Development, 32(6): 316-318.

[11] Pellet, J. (2009). What's wrong with CEOs Succession? Chief Executive Officer. 240.

[12] Board of Directors, North American Public and Private Sectors (2010). Three Models of Succession Planning.

[13] Wilson, T. (2015). Eight (8) Steps for Effective Succession Planning. Inspiration from Leading Industry and Human
Resource (HR) Experts.

[14] Onuoha, B. C. (2013), Poor Succession Planning by Entrepreneurs: The Bane of Generational Enterprises in South-East, Nigeria, AFRREV IJAH: International Journal of Arts and Humanities, 2(2), 270-281.

[15] Ogundele, O. J. K., Idris, A. A., \& Ahmed-Ogundipe, K. A., (2012), Entrepreneurial Succession.

[16] Musa, B. M., \& Semasinghe, D. M. (2014), Leadership Succession Problem: an Examination of Small Family Businesses, European Journal of Business and Management, 6(34), 301-306.

[17] Onuoha, B. C. (2013), Wealth Creation, Retirement and Succession Planning of Entrepreneurs in South-East, Nigeria, International Business and Management, 7(1), 99-105.

[18] Hall, D. T. (1986), Dilemmas in Linking Succession Planning to Individual Executive Learning, Human Resource Management, 25 (2): 235-265.

[19] Huang T (1999). Succession planning and management, Charity Village Library, Available onlineat:www.charityvillage.com/topics/human-resources/hrplanning/succession- planning.

[20] Diamond P. (2006). Meaningful work, employee engagement, and other key employee outcomes: Implications for human resource development. Advances in Developing Human Resources, 13(4), 508-525.

[21] Shen, W. \& Cannela, A. (2003) Will succession planning increase shareholders wealth? Strategic Management Journal, 24(2), 191-198.

[22] Schall B., (1997). Four Emerging Perspectives of Employee Engagement: An Integrative Literature Review. Human Resource Development Review, 10(3), pp. 304-328.

[23] Aderonke, J. (2014). Culture Determinants and Family Business Succession in Jos Metropolis, Plateau State Nigeria, Journal of Emerging Trends in Economics and Management Sciences, 5(5), 379-390.

[24] Balloun, J. \& McGill, J. (2005). Succession Planning: A Critical Boardroom Imperative, NACD Directors Monthly, 29(9).

[25] Bjuggren, P and Sund, L (2001) 'Strategic Decision Making in Integration Successions of Small and Medium Size Familyowned Business', Family Business Review, 14 (1):226-229.

[26] Bowen, M., Morara, M. \& Mureithi, S. (2009). Management of Business challenges among small \& Micro enterprises in Nairobi- Kenya: KCA. Journal of Business Management, 2.

[27] Charan, R. (2005). Ending the CEO Succession Crisis. Harvard Business Review, 83(2).

[28] Chung-Herrera, B. G, Enez, C. A. \& Lankau, M. J. (2003), Grooming Future Hospitality Leaders: A Competencies Model, Cornell Hotel and Restaurant Administration Quarterly, 44(3), 17-25.

[29] Dauda, Abdulwaheed (2013). Business Continuity and Challenge of Succession in Nigeria: What Happens When the CEO Leaves? Journal of Business and Management, PP 5965 .

[30] Davis, N. (2008, April). Succession planning not limited to the C-suite. HRMagazine, 69-70. 
[31] Dessler, G. (2010). A Framework for Human Resources Management Upper Saddle River, NJ. Pearson Education Inc.

[32] Eager, S. W. (2017). Decent and Distribution: Intestate Succession in the State of New York. Albany, NY. Bender \& Co.

[33] Eru, Kobe Godwin (2013). Keys to Effective Succession Planning, http://www.connectnigeria./keys-to-effectivesuccession- planning/

[34] Herman, S. (2015). Succession Planning: Internal Candidates vs External Recruitment. Los Angeles, Califonia, United State.

[35] Howe, S. M. (2005), the Leader of the Future; New Visions, Strategies, and Practices for the Next Era, Succession Planning, San Fransisco: Jossey-Bass.

[36] Husain, J. (2009). Lessons Learnt from business mentoring practices. The Business Review. 14 (1). Cambridge, England.

[37] Jaques, E. (1989). Requisite Organization: the guide to creative structure and leadership. Cason Hall. ISBN: 096210700x

[38] Johnson, G. L. and Brown, J. (2015). Workforce Planning: Not a Common Practice. Journal of Management Science, 33(4): 379-388.
[39] Mathias, R. L., and Jackson, J. H. (2006), Human Resource Management, Eleventh Edition, South-Western College Publication

[40] Newton, C. (2001). The Advantages of Recruiting New Employees. Small Business in Managing Employees.

[41] Lawson, E. (2010). Retaining Key Employees in Terms of Challenges. McKinsey Quarterly. Pp. 168-173.

[42] Ohuabunwa, M. S. (2015). The challenge of succession planning in Nigeria.www.hopefornigerianponline.com

[43] Ohmae, K., (2005). The Coming of Global Competition, New York, Free Press

[44] Osibanjo, O. A., Abiodun, J. A. \& Obamiro, J. K., Succession Planning and Organizational Survival: Empirical Study on Nigerian Private Tertiary Institutions, Serbian Journal of 45 Management, 6 (2) (2011) $231-246$.

[45] Problems in Nigeria's Family Businesses: a Threat to Sustainability. European Scientific Journal, 8(7), 208-227.

[46] Turcknett Leadership Group (2013). Executive Assessment and Selection Succession Planning. Competency Model, (770): 270-1723. 